\title{
Crop-livestock integration determines the agroecological performance of mixed farming systems in Latino-Caribbean farms
}

\author{
Fabien Stark ${ }^{1,2}$ - Eliel González-García ${ }^{3}$ - Livia Navegantes ${ }^{4} \cdot$ Taymer Miranda $^{5}$ - René Poccard-Chapuis ${ }^{2}$. \\ Harry Archimède ${ }^{6}$. Charles-Henri Moulin ${ }^{7}$
}

Accepted: 4 December 2017 / Published online: 21 December 2017

(C) The Author(s) 2017. This article is an open access publication

\begin{abstract}
Characterizing and understanding the complexity of numerous interactions occurring in mixed farming systems is still a methodological challenge. We hypothesize that farm functioning features in terms of crop-livestock integration practices impact the agroecological performance of the system, which will be also affected by the farm context. In order to analyze crop-livestock integration in a holistic way, a set of seventeen mixed farming systems from three contrasting socioeconomic regions of the humid tropics (Guadeloupe, Brazilian Amazonia, and Cuba) was selected in order to cover a wide range of crop-livestock integration situations. The ecological network analysis was applied to each farm in order to study the nutrient flow networks, expressed in nitrogen. The activity and flow organization of crop-livestock integration practices were characterized and the agroecological performance has been evaluated in terms of efficiency, resilience, productivity, and dependency of $\mathrm{N}$ flow networks. Here, we show for the first time that the range of crop-livestock integration is well characterized by the activity and organization of flows. Gradients of crop-livestock integration were well detected and described. Some agroecological performances were related to a particular socioeconomic context. Resource endowment influenced efficiency, according to the intensification level. The crop-livestock integration however contributed partially to the productivity of the system, being especially effective in promoting resilience. This study applies a suitable framework to analyze complex farming systems while linking their functioning and performance in an agroecological approach. Thus, comparison of contrasting systems was feasible here with the support of numerical and tangible figures for interpreting complex indicators (e.g., resilience), representing a useful tool for monitoring sustainability of agricultural systems in a dynamic and holistic way.
\end{abstract}

Keywords Ecological network analysis · Multicriteria assessment · Nitrogen flows · Productivity · Resilience - Efficiency · Dependency $\cdot$ Cuba $\cdot$ Brazil $\cdot$ Guadeloupe

Fabien Stark

fabien.stark@agreenium.fr

Eliel González-García

eliel.gonzalez-garcia@inra.fr

Livia Navegantes

lnavegantes@ufpa.br

Taymer Miranda

miranda@ihatuey.cu

René Poccard-Chapuis

rene.poccard-chapuis@cirad.fr

Harry Archimède

harry.archimede@inra.fr

Charles-Henri Moulin

charles-henri.moulin@supagro.fr
Agreenium, UMR Innovation, Paris, France

2 SELMET, Univ Montpellier, CIRAD, INRA, Montpellier SupAgro, CIRAD, Montpellier, France

3 SELMET, INRA, Montpellier SupAgro, CIRAD Univ Montpellier, INRA, Montpellier, France

4 Núcleo de Ciências Agrárias e Desenvolvimento Rural, UFPA, Belém, Pará, Brazil

5 Estación Experimental de Pastos y Forrajes "Indio Hatuey", Central España Republicana, Matanzas, Cuba

6 URZ, Centre Antilles Guyane, Petit-Bourg, Guadeloupe, France

7 SELMET, Montpellier SupAgro, INRA, CIRAD, Univ Montpellier, Montpellier, France 


\section{Introduction}

Agricultural systems face the challenge of producing more and better in a fast-changing world. Future farming systems must become more productive, if they are expected to feed a growing population, more efficient at using the available resource bases (Garnett et al. 2013), more resilient or less dependent, and thus, less vulnerable to unpredictable hazards (Darnhofer et al. 2010). In this context, the conceptual framework of agroecology seems relevant in meeting these goals (Altieri et al. 2012) through the application of ecological concepts and principles for the design and management of sustainable agroecosystems. Mixed farming systems, which account for almost the half of current world food production and are present in all edaphoclimatic areas (Herrero et al. 2010), could provide sound alternatives to progressively achieve these goals (González-García et al. 2012). Especially in the humid tropics, agriculture is supported by a significant role and presence of mixed farming systems, often in a context of subsistence and smallholder agriculture (Fig. 1).

Several authors highlight the benefits of crop-livestock integration in mixed farming systems (Ryschawy et al. 2012), in terms of sustainable food production, livelihood improvement (Herrero et al. 2010) or efficiency (Thorne and Tanner 2002). Others consider crop-livestock integration at a practical level to improve resources used (Rufino et al. 2009), animal feeding conditions (Archimède et al. 2014), and manure management or crop residues used (Tittonell et al. 2015). However, studying this kind of complex interactions is still a challenge for the scientific community.

We make the assumption that crop-livestock integration, by involving complex resource exchanges and cycle interactions between crop and livestock production sub-systems, is expected to play an essential role in mixed farming systems' functioning and performance, considering an agroecological perspective (Sumberg 2003). Bonaudo et al. (2014) suggest four emergent agroecocological properties related to mixed farming systems: resilience, productivity, efficiency, and dependency, but do not provide indicators to assess these criteria.

Most of the available literature is still presenting interpretation of result outputs since a theoretical or descriptive point of view. Still, there are few studies available at the literature however characterizing crop-livestock integration as a whole process of resource exchanges at the system level and enabling the true assessment of associated performances (González-García et al. 2012). The studies which most closely meet this objective analyze crop-livestock integration based on nutrient flow networks (Rufino et al. 2009). Using the ecological network analysis methodology, an approach used in ecology to model ecosystems in flow networks to assess their properties (Fath et al. 2007), these studies explore mixed farming systems' performance in terms of resource endowments and technical performances. Stark et al. (2016) proposed an advanced improvement of this methodology by developing a consistent and combined set of ecological and agronomical indicators for characterizing and assessing both crop-livestock integration features and agroecological performances of mixed farming systems. However, this study, based on a limited sample of case studies with too similar characteristics, did not highlight the relationships between croplivestock integration and impacts on agroecological performance of farms.

The aim of the present study is thus to assess the agroecological performances of a wide range of contrasted croplivestock integration practices at the farming system level, based on the methodology provided by Stark et al. (2016). We hypothesize that farm functioning features in terms of crop-livestock integration practices will determine its agroecological performance of the system, which will be also affected by the farm context.

\section{Materials and methods}

\subsection{Study sites and sampled farms}

In order to compare several forms of crop-livestock integration, we carried out this study on three contrasting territories in the humid tropics: Guadeloupe, Brazilian Amazonia, and

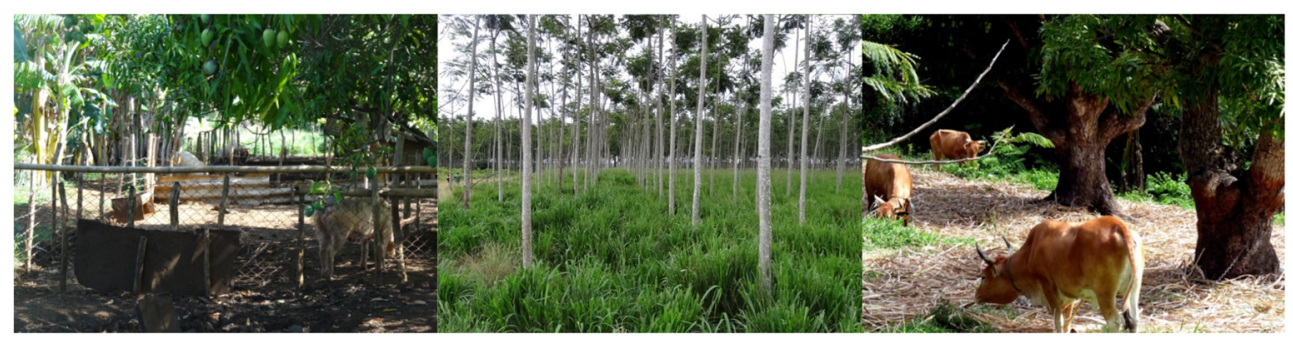

Fig. 1 Example of mixed farming systems and crop-livestock integration practices in the three Latino-Caribbean territories. Cuba: pig and fruit systems associated to feed and fertilize themselves; Brazil: association of tree and pasture to wood production and cattle feeding; Guadeloupe: cattle feeding through sugarcane distribution, grazing and fruits, and organic fertilization of pasture and trees 
Cuba, thus covering a wide range of crop-livestock integration patterns.

The analysis was carried out on three territories with contrasted situations of access to production factors. It is assumed that shortage of land or capital would limit the implementation of integration practices at the farm level; in contrast, labor availability would encourage the implementation of crop-livestock integration practices (González-García et al. 2012).

Guadeloupe is a French insular archipelago in the Caribbean Sea (latitude $16^{\circ} 13^{\prime} \mathrm{N}$, longitude $61^{\circ} 34^{\prime} \mathrm{W}$ ) where agriculture is characterized by low access to land (average of 4.1 ha per farm) and mixed systems ( $80 \%$ of farms). In comparison with other Caribbean countries, the access to capital is significant with a high labor costs, because of subsidies from France and European Union. Moreover, European regulations guide practices and productions.

In Brazilian Amazonia, (Paragominas municipality, state of Pará, latitude $2^{\circ} 58^{\prime} \mathrm{S}$, longitude $47^{\circ} 29^{\prime} \mathrm{W}$ ), family agriculture situations were selected as mixed farms rather than the more specialized big farms ("fazendas") (Macedo 2009). Such smallholders present a relative high access to land, compared to Caribbean islands (between 20 and 100 ha), moderate access to labor, and low resource endowment.

Cuba is the largest island of the Caribbean and in the Matanzas province (latitude $23^{\circ} 02^{\prime} \mathrm{N}$, longitude $81^{\circ} 34^{\prime}$ $\mathrm{W})$; as in the rest of the country, the agriculture shifted from big state farms during the Soviet Union relationship period to a certain land redistribution to small farmers (Febles-González et al. 2011; Altieri et al. 2012). Small farms are characterized by moderate access to land and significant access to labor due to the limited number of other job opportunities, the low labor cost of the socioeconomic system, and limited access to capital, but also due to the leveraging of old equipment and local resources, strongly supported by an organized system of research, education, and development.

For the implemented study design, the sample of farming systems consisted on selecting seventeen farms covering a wide range of integration practices (Table 1). The farms were chosen according to previous exploratory studies carried out in Guadeloupe $(n=8)$ and Brazil $(n=4)$, and according to current research-development projects running in Cuba $(n=$ 5). For each of these three contrasted regions, the sampling objective was to identify mixed farming systems representing various practices of crop and livestock integration to have an overview of diversified farming systems of each region. Finally, these mixed farming systems combine between two and eight productions, with at least one crop and one livestock production per farm whereas livestock activities concern mainly cattle $(n=13)$ and pigs $(n=12)$. In Guadeloupe and Brazil (except in one case), ruminants graze permanent grasslands without using forage crops. Crop activities concern forage crops for Cuba, export crops (sugarcane and banana) for
Guadeloupe, and market gardening in Guadeloupe and Cuba, staple food crops for human feeding and fruit crops for the three sites.

\subsection{Data collection}

To assess the crop-livestock integration and the performance of the whole production system, we used the ecological network analysis, previously adapted to farming system analyses by Rufino et al. (2009) and improved to agroecological performance analysis of farming systems by Stark et al. (2016) but applied on a limited number of samples or replicates (i.e., farms) in Guadeloupe.

The data were collected by performing three to four semistructured interviews to each farmer using a comprehensive approach to farming systems (Marshall et al. 1994). Qualitative and quantitative data concerning resource endowment, land use, crop and livestock activities, and management practices were collected, in order to depict the farm operation along one whole-round production campaign. The generic production system was described for each farm by establishing existing compartments, interactions, and flows among systems, sub-systems, and implied processes (Fig. 2).

All the flows were estimated on a year-basis based on the same previous annual campaign per region, and expressed in $\mathrm{N}$, due to the important role of $\mathrm{N}$ for both crop and livestock production development (Rufino et al. 2009). Flows were calculated considering the quantity of biomass exchanged (information gathered from the interviews) and the biomass content (estimated using local scientific available data). Some biomass flow estimations could not be established from the performed interviews, i.e., the ruminant's total forage intake, livestock excretion, and emissions linked to manure or mineral fertilization. Rather, we estimated the intake considering zootechnical parameters like farm animal species and liveweight (Agabriel 2010). The overall amount of $\mathrm{N}$ excreted was thus estimated as the total $\mathrm{N}$ intake minus total $\mathrm{N}$ exported through animal products. The $\mathrm{N}$ emissions from manure were estimated from Peyraud and Cellier (2012) according to the established husbandry management in the farm, the manure source, and other further process steps. As N emissions from fertilization are highly variable, according to climate and soil, type of fertilizer, conditions of application, and crop, we assumed an emission coefficient of $2.6 \%$ of $\mathrm{N}$ applied irrespective of the situation (Reay et al. 2012).

A matrix was thus drawn up for each farm case, with the origin of flows in the columns (inputs from exterior and compartments), the destination of flows in the rows (compartments, outputs, and losses), and the annual amount of $\mathrm{N}$ exchanged at the intersection.

Flows are expressed in kilograms of $\mathrm{N}$ per hectare per year and move from one compartment $(j=0, \ldots n ; 0$ 


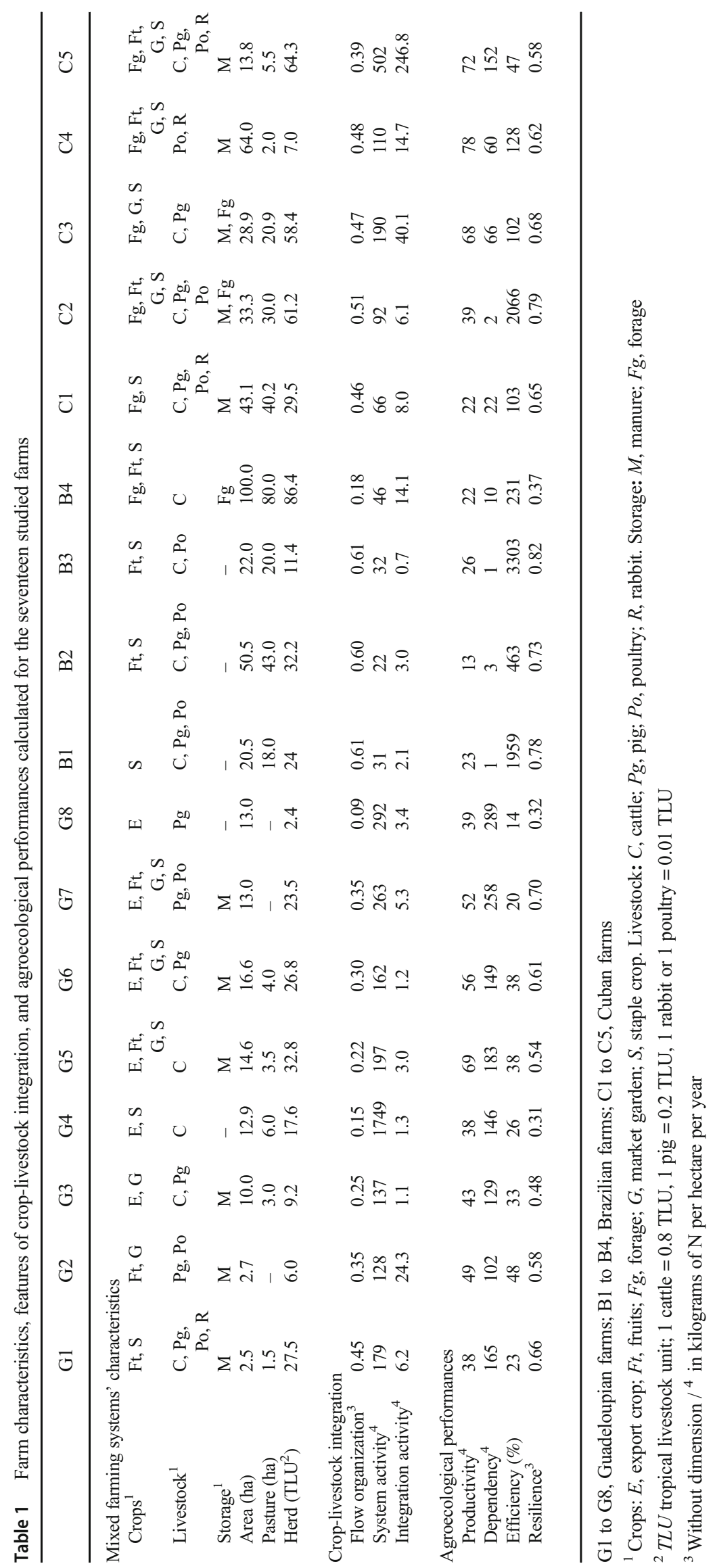




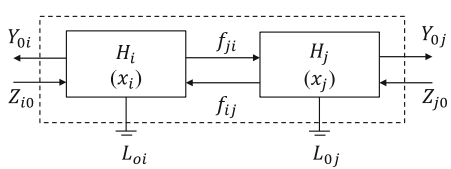

Fig. 2 Theoretical two-compartment network model with information required to perform ecological network analysis (adapted from Finn 1980) and the common conceptual model performed to analyze the farming systems of this study. According to Latham (2006) convention, each farming system is characterized by the following elements: $n$ the number of compartments; $H_{i}$ and $H_{\mathrm{j}}$, the compartments $i$ and $j ; \dot{x}_{i}$ and $x_{\mathrm{j}}$

corresponding to the importation from external environment and $n$ the number of compartments) to another ( $i=1$, $\ldots, n+1, n+2)$, where $n+1$ accounts for usable exports (usable exported animal and vegetal products) and $n+2$ accounts to unusable exports or losses. Based on the characteristics of the sample, the crops are aggregated into five cropping compartments (forage, staple, export, fruit, and market gardening crops). Each animal species is represented by a compartment (cattle, pigs, poultry, and rabbits). In the case of ruminants, permanent grasslands and livestock are gathered in a sole compartment (grazing cattle). Two storage compartments represent manure and forage conservation. Flows correspond to throughflows between compartments (manure and feed), input flows from the outside correspond to mineral fertilizers and animal feed, output flows correspond to usable exported animal and vegetal products, and finally, losses of flows correspond to emissions and non-used manure from livestock (building, storage, and grazing) and emissions from crops (manure and mineral fertilizer applications).

\subsection{Data analysis}

From this matrix, two sets of indicators are calculated using the framework developed and described by Stark et al. (2016) to characterize crop-livestock integration and to assess agroecological performances.

The first set of three indicators allows characterizing the crop-livestock integration. The system activity is assessed by the total system throughflows (Eq. 1) as the sum of all the throughflows $T_{i}$ (Eq. 2), with $f_{i j}$ as the flow between

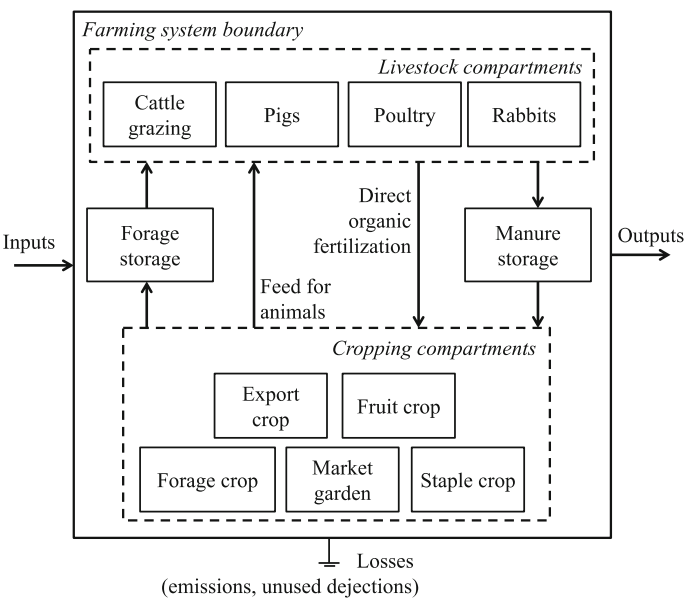

the states derivative for compartment $i$ and $j$; $f_{i j}$ the internal flows from compartment $H_{j}$ to compartment $H_{i} ; Y_{0 i}$ and $Y_{0 j}$ the outflow from compartment $H_{i}$ and $H_{\mathrm{j}}$ to the external environment; $Z_{i 0}$ and $Z_{j 0}$, the inflow from the external environment to compartment $H_{i}$ and $H_{\mathrm{j}}$; and $L_{0 i}$ and $L_{0 j}$ the unusable exports or losses from compartments $H_{i}$ and $H_{\mathrm{j}}$ to the environment

compartments $i$ and $j, Z_{i 0}$ as the flow into compartment $i$ from outside the network, and $\left(\dot{x}_{i}\right)_{-}$as the negative state derivative for compartment $i$. The state derivative is equal to the inflows minus the outflows over a given time interval. The negative state derivative is equal to $x_{i}$ if $x_{i}<0$ and 0 if $x_{i} \geq 0$ (Latham 2006).

$\mathrm{TST}=\sum_{\mathrm{i}=1}^{\mathrm{n}} \mathrm{T}_{\mathrm{i}}$

$T_{i}=\sum_{j=1}^{n} f_{i j}+Z_{i 0}-\left(x_{i}\right)_{-}$

The crop-livestock integration activity is appreciated through the total internal throughflows (Eq. 3), which quantifies the amount of matter circulating among compartments:

$\mathrm{TT}=\sum_{\mathrm{i}=1}^{\mathrm{j}=\mathrm{n}} \mathrm{f}_{\mathrm{ij}}$

The viewpoint of the information theory applied to ecological stability (Rutledge et al. 1976) is used to assess the flow organization. This indicator, according to the pattern of the network connections, is calculated through the realized uncertainty $\left(\mathrm{AMI} / H_{r}\right)$, quantifying the actual pattern of flows in terms of the potential distribution of flows divided equally among all compartments. The average mutual information (AMI) quantifies the organization of the flows (Eq. 4), for which $T_{i j}$ is the sum of the flows from compartments $j$ to compartment $i ; T_{. .}$is the total system throughput, corresponding to the sum of the network links; $T_{i .}$ and $T_{. j}$ are the total inflow for compartment $i$ and for compartment $j$, respectively; and $k$ is a constant scalar.

AMI $=\mathrm{k} \sum_{\mathrm{i}=1}^{\mathrm{n}+2} \sum_{\mathrm{j}=0}^{\mathrm{n}} \frac{\mathrm{T}_{\mathrm{ij}}}{\mathrm{T}_{. .}} \log _{2} \frac{\mathrm{T}_{\mathrm{ij}} \mathrm{T}_{. .}}{\mathrm{T}_{\mathrm{i} .} \mathrm{T}_{. \mathrm{j}}}$ 
The statistical uncertainty $\left(H_{r}\right)$ is the upper boundary for AMI (Eq. 5):

$$
H_{r}=-\sum_{j=0}^{n} \frac{T_{. j}}{T . .} \log _{2} \frac{T_{. j}}{T . .} .
$$

The more the realized uncertainty $\left(\mathrm{AMI} / H_{r}\right)$ is close to 1 , the more the flows are concentrated on some compartments (some potential flows are null) and the more the existing flows exhibit a high variability of amount. In that case, the flow organization is said to be heterogeneous. Due to the evolution of this ratio, we consider the indicator of flow organization as $1-\mathrm{AMI} / H_{r}$, meaning that as far the indicator get close to 1 , the more the pattern of flows is distributed equally among all compartments and the more the network of flows is said to be homogeneous (for a better understanding of the realized uncertainty calculation, see Rufino et al. (2009) who provided a simple numerical application).

A second set of four indicators, assessing the system performances, is inspired by the criteria proposed by Bonaudo et al. (2014): resilience, productivity, efficiency, and dependency. The resilience indicator comes from information sciences and allows to characterize the capacity of an ecosystem for recovering from disturbances, inspired of the ascendency suite developed by Ulanowicz (2004). It corresponds to the actual reserve capacity allowed by the configuration of the network of flows in function of the maximum potential capacity of the system, allowed by the amount of all flows. It is calculated as the ratio between the overhead ( $\phi$, Eq. 6) and the development capacity ( $C$, Eq. 7$)$. The more the ratio is closer to 1 means that the system keeps reserve capacity for recovering from disturbances.

$$
\begin{aligned}
& \phi=-\sum_{i . j} T_{i j} \log \left(\frac{T_{i j}^{2}}{T_{i .} T_{. j}}\right) \\
& \mathrm{C}=-\sum_{\mathrm{i} . \mathrm{j}} \mathrm{T}_{\mathrm{ij}} \log \left(\frac{\mathrm{T}_{\mathrm{ij}}}{\mathrm{T}_{. .}}\right)
\end{aligned}
$$

Indicator of productivity is calculated as the sum of valuable $\mathrm{N}$ outputs whereas the indicator of dependency is the sum of $\mathrm{N}$ inputs. The two sums are divided by the agricultural area of the farm. The efficiency is defined as the ratio between the $\mathrm{N}$ flow productivity and the $\mathrm{N}$ flow dependency.

The data are organized through a spreadsheet in order to build the matrix of flows for each farm. Some indicators may be calculated directly from the matrix (crop-livestock integration activity, productivity, dependency, efficiency). The other indicators are calculated by using the $\mathrm{R}$ software, with the package enaR (Lau et al. 2017). After performing univariate and bivariate analyses, a principal component analysis was carried out with six indicators by using the $\mathrm{R}$ software (Lê et al. 2008). Efficiency was not included as an indicator, due to the strong correlation with productivity and dependency.
Moreover, one farm was removed (C5), as it was too distant from the sample and tended to smooth out the overall results.

\section{Results and discussion}

\subsection{Agroecological performances of a set of several forms of mixed farming systems}

Depending on regions (Table 1), productivity ranged from 13 to $72 \mathrm{~kg} \mathrm{~N} \mathrm{ha}^{-1}$ and dependency from 1 to $289 \mathrm{~kg} \mathrm{~N}^{-1}$. Resilience ranged from 0.31 for the less resilient systems to 0.82 . The efficiency as the ratio between the $\mathrm{N}$ flow productivity and $\mathrm{N}$ flow dependency is useful in characterizing the performance profiles of various situations (Fig. 3). The cases above the line presented $\mathrm{N}$ efficiency results higher than $100 \%$, meaning that they export more $\mathrm{N}$ than what they import. These situations correspond mainly to the Brazilian cases, which have low levels of outputs (between 13 and $26 \mathrm{~kg} \mathrm{~N} \mathrm{ha}^{-1}$ ), but much lower levels of inputs (between 1 and $10 \mathrm{~kg} \mathrm{~N} \mathrm{ha}^{-1}$ ), leading to very high levels of apparent $\mathrm{N}$ efficiency (between 231 and 3303\%). The cases below the line have efficiency results lower than $100 \%$, meaning that they import more $\mathrm{N}$ than what they export. These situations corresponded to all the Guadeloupian cases which have high levels of inputs and intermediate levels of outputs, and consequently, low levels of $\mathrm{N}$ efficiency. Noteworthy was the fact that two Guadeloupian cases showed very high levels of inputs, without being particularly productive nevertheless, and generating the lowest level of $\mathrm{N}$ efficiency. The Cuban cases showed intermediate levels of performance. Two of them presented low levels of production and consume a low level of $\mathrm{N}$ resources, similar to the Brazilian cases. One Cuban farm is similar to the Guadeloupian tendency, with a high level of inputs and an intermediate level of outputs. Two other cases have a high level of outputs while consuming relatively low quantity of $\mathrm{N}$ resources, thus leading to high level of $\mathrm{N}$ efficiency.

An interesting parallel can be drawn between the results obtained in this study, from real case studies, and the theoretical framework proposed by Bonaudo et al. (2014). These authors conceptualized trajectories of archetypes from conventional intensification (high-chemical-input systems) or ecologization (low-chemical-input systems) to agroecological intensification. Situations analyzed in our study provide empirical evidence nuancing this theoretical framework. Ecologization could be assimilated to a part of the Brazilian and Cuban farm cases, with low levels of inputs and outputs. Conventional intensification could be assimilated to the Guadeloupian cases and one Cuban case, which presented high levels of inputs and outputs, and, finally, the notion of an agroecological intensification tendency could be assimilated to two Cuban cases, which showed low inputs 


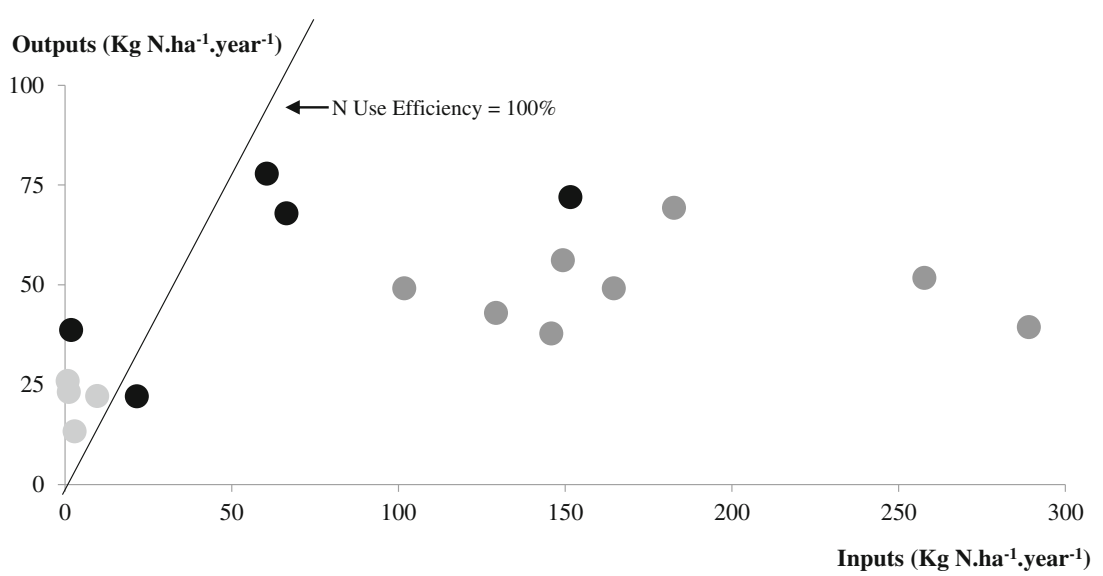

Fig. 3 Nitrogen productivity in function of $\mathrm{N}$ dependency of the seventeen studied farms. This graph presents the productivity (expressed as the outputs in kilograms of $\mathrm{N}$ per hectare per year) according to the dependency (expressed as the inputs in kilograms of $\mathrm{N}$ per hectare per year). The curve represents the value of $100 \%$ for the $\mathrm{N}$ use efficiency ( $\mathrm{N}$ outputs $=\mathrm{N}$ inputs). In pale gray, Brazilian case studies; in dark gray, Guadeloupian case studies; and in black, Cuban case studies and high levels of outputs, respectively. We perceived that the theoretical framework proposed by Bonaudo et al. (2014) focusing in the intensification level is consistent with extreme situations of conventional intensification and ecologization. However, a broad range of intermediate situations coexists as showed by our results, for which the notion of intensification and ecologization is not sufficient to characterize them.

Moreover, this theoretical framework fails to encompass the farm resilience dimension, considered as an essential feature of agroecological farming systems, which is rarely, see ever, calculated by assessment studies. Resilience was taken into account and measured in our study, as the potential resilience (i.e., better, more flexible capacity to overcome disturbances) allowed by the pattern of $\mathrm{N}$ flows (Ulanowicz 2004). Consequently, the agricultural practices, modeled as a network of flows, strongly impact the resilience profiles, given that indirect pathways are less efficient in terms of $\mathrm{N}$ use, but provide adaptive capacity to the system as alternative pathways for flows. The resilience approach used in this study is based on a biotechnical view and is consistent with the other performances assessed. However, this choice does not allow to take into account the social or economic dimensions of resilience as expected for the analyses of socio-ecosystems (Darnhofer et al. 2010), but lays the groundwork for more inclusive further studies.

\subsection{Crop-livestock integration as a complex network of flows}

A new focus on the way of analyzing complex systems was performed by considering crop-livestock integration according to the activity of flows and by their organization as a network (Stark et al. 2016). To improve the analysis and the characterization of crop-livestock integration practices, our study is based on the same framework but applied to a wide range of situations.

The indicators of flow organization, ranged from 0.09 in the more heterogeneous networks of flows to 0.61 for more homogeneous ones. The crop-livestock integration activity ranged from less than $1 \mathrm{~kg} \mathrm{~N} \mathrm{ha}^{-1}$ for which crop-livestock integration contributed very slightly to the system activity to $247 \mathrm{~kg} \mathrm{~N} \mathrm{ha}^{-1}$ for systems for which crop-livestock integration strongly contributed to system activity. When these results are combined, four types of crop-livestock integration practices could be identified, i.e., systems with low integration activity $\left(<3.4 \mathrm{~kg} \mathrm{~N} \mathrm{ha}^{-1}\right)$ concentrated on few flows (flow organization $\mathrm{AMI} / H_{r}<0.3$ ), which corresponded to the majority of Guadeloupian cases, excepted for three of them that showed quite integration activity and better flow organization (G1, G2, G7). Systems with low integration activity $(<3 \mathrm{~kg} \mathrm{~N}$ $\left.\mathrm{ha}^{-1}\right)$ and homogeneous flow organization $(\geq 0.6)$ correspond to most Brazilian cases. Systems with high integration activity $\left(>8 \mathrm{~kg} \mathrm{~N} \mathrm{ha}^{-1}\right)$ spread more or less homogeneously $(0.3 \leq$ flow organization $\leq 0.51$ ), corresponding to most of Cuban farm cases and some Guadeloupian farms. One farm with high integration activity was concentrated on only few flows presented in the farm, which corresponded to one Brazilian case (B4), due to the use of corn silage. This framework, applied to a wide range of mixed farming systems, bring new opportunities to consider agricultural practices at farming system level, considering both livestock and cropping systems on the same dimension, and allowing to take into consideration emergent properties which result from the actual configuration of the system. The study was performed through nitrogen flows. But considering the limited availability of phosphorus in ferrallisols, frequent in east Amazonia or in Guadeloupe, the cycling of phosphorus from organic pools is of particular significance (George et al. 2006). It could be relevant to study 
PCA distribution of variables

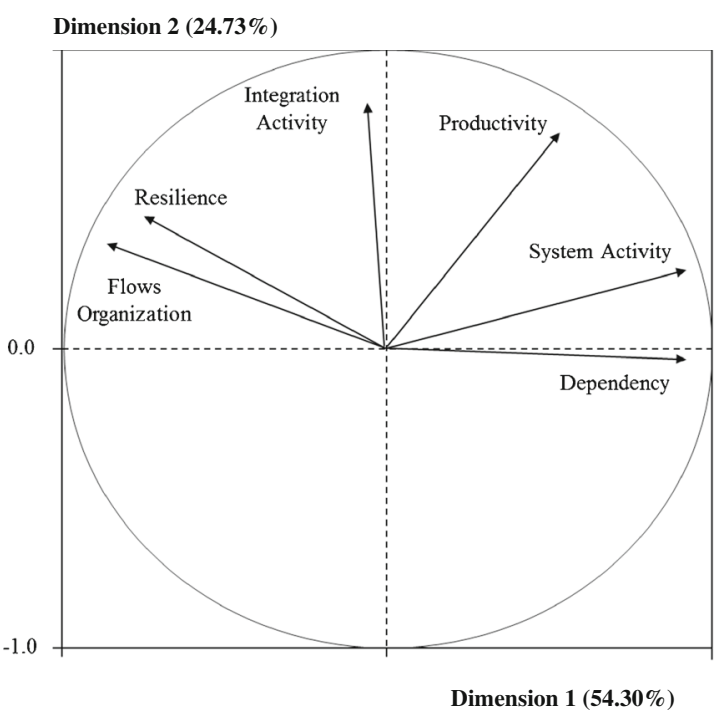

Fig. 4 Principal component analysis of sixteen studied farms according to crop-livestock integration and agroecological performance indicators. Results coming out from the principal component analysis output, on the two first dimensions (explaining 79\% of variability). The first graph represents the distribution of variables and shows correlations between

the flows of phosphorus in order to also assess the croplivestock integration from the viewpoint of this nutriment.

\subsection{Agroecological performances according to crop-livestock integration features}

Multivariate analysis on variable results (Fig. 4) shows that system activity and dependency are positively correlated between them and negatively correlated to the flow organization and resilience, which nevertheless are correlated between them. These results suggest that the amount of $\mathrm{N}$ circulating through the system is mainly due to the quantity of $\mathrm{N}$ entering to the system and that the homogeneously organization of flows is strongly linked to the potential of resilience of the system. An outstanding result is also that these properties are negatively correlated, meaning that the farming systems exhibiting the more homogeneous flow network are the less dependent ones, independently of the quantity of $\mathrm{N}$ circulating between compartments through crop-livestock integration practices. The integration activity is non-correlated with dependency, whereas the flow organization is non-correlated with $\mathrm{N}$ productivity. Contrary to the assumption we made, the integration activity is not directly linked to $\mathrm{N}$ dependency, as $\mathrm{N}$ productivity which is partially correlated to $\mathrm{N}$ dependency, suggesting that other determinants are involved in the production process at farming system level. Indeed, relative nitrogen efficiency of each production is not the same and combination of these productions at farming system level will influence overall productivity and dependency, independently
PCA distribution of individuals

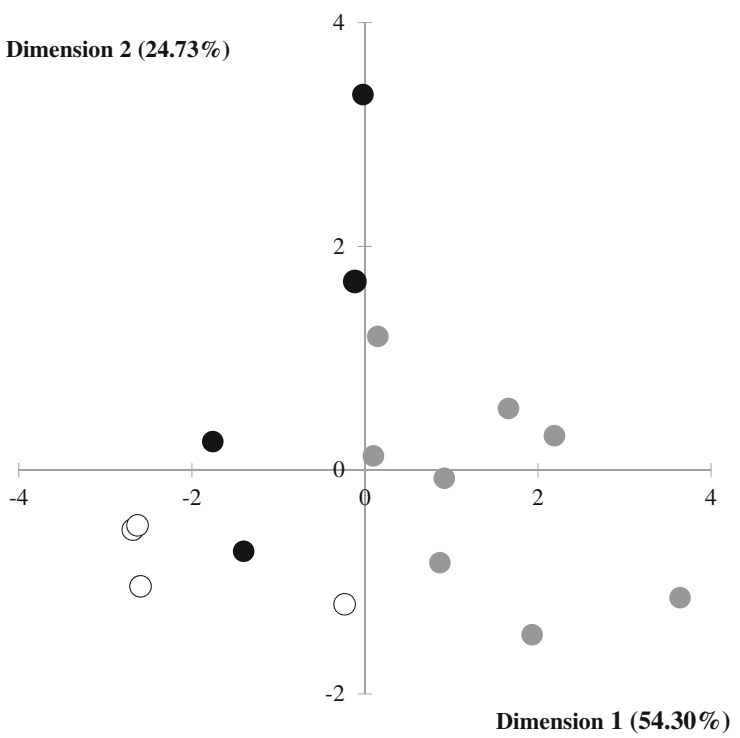

crop-livestock integration and agroecological performance indicators. The second graph represents the distribution of individuals, farm case studies, according to the indicators considered. In white, Brazilian case studies; in gray, Guadeloupian case studies; and in black, Cuban case studies

of farming practices developed. Indeed, the local edaphic and climatic conditions are various between cases, even in a same area. The cycles of nutrient and the management practices (as tillage, fertilization...) are different for each case. Farmers manage their crops and livestock according to the local conditions they perceived and, in consequence, drive partially those processes, leading to various level of $\mathrm{N}$ efficiency for the different crops, but also for a same crop between farms. Our aim was not to explain those differences but to explore if the integration practices are determinant in the overall performances of the farming systems.

The individual results (Fig. 4) suggest four groups of mixed farming systems, according to the observed features of croplivestock integration and their inherent agroecological performances. Three groups are characterized by a low level of integration activity. The first group is characterized by a homogeneous flow organization and could be therefore qualified as resilient in terms of $\mathrm{N}$ flow networks, with low levels of system activity, inputs, and outputs. This group corresponds to the Amazonian and some Cuban cases, relatively extensive, consuming few inputs, with low productivity but recycling several crop residues and manure in small quantity. At the opposite, a group is characterized by heterogeneous flow organization (disproportion between throughflows, inputs, and outputs) and therefore, low resilience performance, high level of inputs, and an intermediate level of outputs (three Guadeloupian cases). This group corresponds to more intensive case studies, consuming a large amount of inputs without achieving substantial levels of productivity, and recycling 
residues and manure marginally. An intermediate group, with a medium flow organization, has intermediate levels of inputs and outputs. This group corresponds to case studies showing a better level of production according to the level of inputs used, developing more crop-livestock integration practices of small amount. Finally, a fourth group is characterized by a high level of integration activity, with an intermediate to high level of outputs. Note that one case (C5) which was removed for the multivariate analysis corresponded to an extreme situation, with very high level of crop-livestock integration and high levels of outputs and inputs. These farms correspond to the more efficient ones, achieving the higher level of productivity by a moderate use of inputs and by several crop-livestock integration practices of consistent amount.

All the performances are calculated from a given 1-year functioning of the farms. It would be interesting to test the interannual variability of the results, from a long-term monitoring, and to verify the consistency of the groups along the years. This pluriannual approach would be particularly relevant to test the theoretical indicator of resilience.

\subsection{Agroecological transition according to farm's crop-livestock integration potential}

The potential for a successful agroecological transition varies according to the type of systems, in terms of regions, resources endowments, combination of productions, and agricultural practices.

Of concern in family agricultural cases in Brazilian Amazonia is the family's food self-sufficiency, with commercialization of the surplus and of some high added value productions. Moreover, the Brazilian mixed farming systems studied presented low resource endowment. Consequently, they have limited purchasing capacity for inputs coupled with limited labor availability, leading to low productivity values but enabling them to meet family food requirements. The challenge is to produce more based on the same or alternative resource uses. The crop-livestock integration could help to achieve these goals through the better use of manure, the introduction of legumes, or agroforestry systems based on natural vegetation (Altieri et al. 2012; Wezel et al. 2014). However, the crop-livestock integration practices require knowledge, labor, and material which are not always necessarily available, particularly in family agriculture in these regions (Hostiou and Dedieu 2009).

The concerns of the Guadeloupian cases are different, even though these cases correspond to small farming systems compared to other specialized farms in the region. Certain specific types of production such as sugarcane, banana, or cattle are highly subsidized. Consequently, Guadeloupian cases have important access to inputs and primarily tend to implement those types of production. However, this could be used to generate a large amount of biomass to be valuable for animal feeding (banana and sugarcane leaves) and manure used for organic fertilization (Archimède et al. 2014; Sierra et al. 2013). Due to the effective cost of manual labor, and the level of equipment required to manage a large amount of biomass, collective initiatives, driven by the most integrated sectors (i.e., banana, sugarcane, or cattle), could be a sound solution to improve the reutilization of crop residues and manure and, by consequence, the self-sufficiency and efficiency of mixed farming systems. The situation of G1 and G2 is rather different. They are very small (less than $3 \mathrm{ha}$ ) and diversified and implement more croplivestock integration practices than other cases in the same region. Agroecological transition, in these cases, could consist of balancing more nutrients between crops and livestock systems in order to optimize the valorization of manure according to crop requirements and by cropping forages to feed their small livestock systems, in order to decrease input dependency at system level while improving productivity.

The Cuban cases are also influenced by their particular socioeconomic context. Cuban agriculture is impacted by the US embargo and by local policies encouraging self-sufficiency. Consequently, input consumption (and dependency) is limited to local input (organic fertilizer, farm forage autonomy, on-farm animal concentrate processed locally, etc.) and production is mostly destined for the domestic market, often under government rules and control. However, the situations on the farms involved in this study are heterogeneous and different in terms of agroecological transition. Cuban agriculture is clearly engaged in an agroecological transition based partly on enhancements of the role of crop-livestock integration practices, with a variety of initial starting points. The challenge would rather concern the capacity of the implemented system of researcheducation-development to maintain the same direction and to disseminate more widely to more farmers in the current changing context. The opening up of the national markets would put in a risky position such agroecological models of agriculture, intensive in labor, probably to the benefit of an intensive model of purchased inputs if effective policies and measures are not taken into account (Nelson et al. 2008).

\section{Conclusion}

Characterizing the crop-livestock integration and quantifying benefits from it is a scientific quest made possible by using the ecological network analysis approach. This study applies a suitable framework to analyze complex farming systems while linking their functioning and performance in an agroecological approach. Thus, comparison of contrasting systems was feasible here with the support of numerical and tangible figures for interpreting complex indicators (e.g., resilience), representing a useful tool for monitoring sustainability of agricultural systems in a dynamic and holistic way. By considering the crop-livestock integration both in terms of structure through the organization of 
flows and in terms of functioning through by the intensity of throughflows, these various agricultural practices could be characterized at whole system level on a common base. Moreover, they enable the relationships between these performances to be analyzed and an appropriate equilibrium to be found between them, ultimately leading to improvements in future farming systems.

The aim of the present study is thus to assess the agroecological performances of a wide range of contrasted crop-livestock integration practices at the farming system level. We hypothesize that farm functioning features in terms of crop-livestock integration practices will determine its agroecological performance of the system, which will be also affected by the farm context. This study highlights the key role played by integration between farming activities to improve agroecological performances of farming systems. Higher intensity of crop-livestock integration flows improves efficiency of the system while more complex and homogenous flow network improves resilience of the system. This study also confirms that the diversity of farming systems leads to different performances, function of their access to production factors, and their socioeconomic contexts. This is especially the case of dependency and productivity which appear to be strongly connected to the characteristics of traditional agricultural systems implemented in each geographical area. However, we show that for similar situations, crop-livestock integration practices could enhance performances, especially resilience and efficiency. According to these situations, solutions to implement further crop-livestock integration should be thought according to regional contexts, both in terms of socioeconomics and soil and climate characteristics.

Acknowledgements The authors would like to thank funding partners that make possible this research project across three countries: the FEADER program (Conseil Régional de Guadeloupe and European Union); the French Embassy in Cuba, CIRAD; and the Académie d'Agriculture de France (Bourse Dufrenoy). We also want to thank the editor and two anonymous reviewers who allowed us to improve this article.

Open Access This article is distributed under the terms of the Creative Commons Attribution 4.0 International License (http:// creativecommons.org/licenses/by/4.0/), which permits unrestricted use, distribution, and reproduction in any medium, provided you give appropriate credit to the original author(s) and the source, provide a link to the Creative Commons license, and indicate if changes were made.

\section{References}

Agabriel J (2010) Alimentation des bovins, ovins et caprins. QUAE éditions, Paris $312 \mathrm{p}$

Altieri MA, Funes-Monzote FR, Petersen P (2012) Agroecologically efficient agricultural systems for smallholder farmers: contributions to food sovereignty. Agron Sustain Dev 32(1):1-13. https://doi.org/10. 1007/s13593-011-0065-6

Archimède H, Alexandre G, Mahieu M et al (2014) Agroecological resources for sustainable livestock farming in the humid tropics. Sustain Agric Rev. https://doi.org/10.1007/978-3-319-06016-3_9
Bonaudo T, Bendahan AB, Sabatier R, Ryschawy J, Bellon S, Leger F, Magda D, Tichit M (2014) Agroecological principles for the redesign of integrated crop-livestock systems. Eur J Agron 57(43):51. https://doi.org/10.1016/j.eja.2013.09.010.

Darnhofer I, Bellon S, Dedieu B, Milestad R (2010) Adaptiveness to enhance the sustainability of farming systems. A review. Agron Sustain Dev 30(3):545-555. https://doi.org/10.1051/agro/2009053

Fath BD, Scharler UM, Ulanowicz RE, Hannon B (2007) Ecological network analysis: network construction. Ecol Model 208(1):49 55. https://doi.org/10.1016/j.ecolmodel.2007.04.029

Febles-González JM, Tolón-Becerra A, Lastra-Bravo X, Acosta-Valdés X (2011) Cuban agricultural policy in the last 25 years. From conventional to organic agriculture. Land Use Policy 28(4):723-735. https://doi.org/10.1016/j.landusepol.2010.12.008

Garnett T, Appleby MC, Balmford A, Bateman IJ, Benton TG, Bloomer P, Burlingame B, Dawkins M, Dolan L, Fraser D, Herrero M, Hoffmann I, Smith P, Thornton PK, Toulmin C, Vermeulen SJ, Godfray HCJ (2013) Sustainable intensification in agriculture: premises and policies. Science 341(6141):33-34. https://doi.org/10. 1126/science. 1234485

George TS, Turner BL, Gregory PJ, Cade-Menun BJ, Richardson AE (2006) Depletion of organic phosphorus from Oxisols in relation to phosphatase activities in the rhizosphere. Eur J Soil Sci 57(1): 47-57. https://doi.org/10.1111/j.1365-2389.2005.00767.x

González-García E, Gourdine JL, Alexandre G, Archimede H, Vaarst M (2012) The complex nature of mixed farming systems requires multidimensional actions supported by integrative research and development efforts. Animal 6(05):763, 777. https://doi.org/10.1017/ S1751731111001923

Herrero M, Thornton PK, Notenbaert AM, Wood S, Msangi S, Freeman HA, Bossio D, Dixon J, Peters M, van de Steeg J, Lynam J, Rao PP, Macmillan S, Gerard B, McDermott J, Sere C, Rosegrant M (2010) Smart investments in sustainable food production: revisiting mixed crop-livestock systems. Science 327(5967):822-825. https://doi. org/10.1126/science. 1183725

Hostiou N, Dedieu B (2009) Diversity of forage system work and adoption of intensive techniques in dairy cattle farms of Amazonia. Agron Sustain Dev 29(4):535-544. https://doi.org/10.1051/agro/2009012

Latham LG (2006) Network flow analysis algorithms. Ecol Model 192(34):586-600. https://doi.org/10.1016/j.ecolmodel.2005.07.029

Lau MK, Borrett SR, Baiser B, Gotelli NJ, Ellison AM (2017) Ecological network metrics: opportunities for synthesis. Ecosphere 8:8. https:// doi.org/10.1002/ecs2.1900

Lê S, Josse J, Husson F (2008) FactoMineR: an R package for multivariate analysis. J Stat Softw 25:1. https://doi.org/10.18637/jss.v025.i01

Macedo MCM (2009) Integracão lavoura e pecuária: o estado da arte e inovacões tecnológicas. R Bras Zootec. https://doi.org/10.1590/ S1516-35982009001300015

Marshall E, Bonneviale JR, Francfort I (1994) Function and global diagnosis of farms. ENESAD

Nelson E, Scott S, Cukier J, Galán ÁL (2008) Institutionalizing agroecology: successes and challenges in Cuba. Agric Human Values 26(3): 233, 243. https://doi.org/10.1007/s10460-008-9156-7

Peyraud JL, Cellier P (2012) Les flux d'azote liés aux élevages, réduire les pertes, rétablir les équilibres. Expertise scientifique collective, rapport, Inra (France), 527 p. http://inra.dam.front.pad.brainsonic. $\mathrm{com} /$ ressources/afile/223277-92bc0-resource-expertise-flux-dazote-rapport-complet.html

Reay DS, Davidson EA, Smith KA, Smith P, Melillo JM, Dentener F, Crutzen PJ (2012) Global agriculture and nitrous oxide emissions. Nat Clim Chang 2(6):410-416. https://doi.org/10.1038/nclimate1458

Rufino MC, Hengsdijk H, Verhagen A (2009) Analysing integration and diversity in agro-ecosystems by using indicators of network analysis. Nutr Cycl Agroecosys 84(3):229, 247. https://doi.org/10.1007/ s10705-008-9239-2 
Rutledge RW, Basore BL, Mulholland RJ (1976) Ecological stability: an information theory viewpoint. J Theor Biol 57(2):355-371. https:// doi.org/10.1016/0022-5193(76)90007-2

Ryschawy J, Choisis N, Choisis JP, Joannon A, Gibon A (2012) Mixed crop-livestock systems: an economic and environmental-friendly way of farming? Animal 6(10):1722-1730. https://doi.org/10. $1017 /$ S1751731112000675

Sierra J, Desfontaines L, Faverial J, Loranger-Merciris G, Boval M (2013) Composting and vermicomposting of cattle manure and green wastes under tropical conditions: carbon and nutrient balances and end-product quality. Soil Res 51(2):142. https://doi.org/10. 1071/SR13031

Stark F, Fanchone A, Semjen I, Moulin CH, Archimède H (2016) Croplivestock integration, from single practice to global functioning in the tropics: case studies in Guadeloupe. Eur J Agron 80(9):20. https://doi.org/10.1016/j.eja.2016.06.004
Sumberg J (2003) Toward a dis-aggregated view of crop-livestock integration in Western Africa. Land Use Policy 20(3):253, 264. https:// doi.org/10.1016/S0264-8377(03)00021-8

Thorne PJ, Tanner JC (2002) Livestock and nutrient cycling in cropanimal systems in Asia. Agric Syst 71(1-2):111-126. https://doi. org/10.1016/S0308-521X(01)00039-7

Tittonell P, Gerard B, Erenstein O (2015) Tradeoffs around crop residue biomass in smallholder crop-livestock systems - what's next? Agric Syst 134:119-128. https://doi.org/10.1016/j.agsy.2015.02.003

Ulanowicz RE (2004) Quantitative methods for ecological network analysis. Comput Biol Chem 28(5-6):321-339. https://doi.org/10.1016/ j.compbiolchem.2004.09.001

Wezel A, Casagrande M, Celette F, Vian JF, Ferrer A, Peigne J (2014) Agroecological practices for sustainable agriculture. A review. Agron Sustain Dev 34(1):1-20. https://doi.org/10.1007/s13593013-0180-7 